\title{
DOS MOTIVOS RECURRENTES EN EL DESENLACE DE LA HISTORIA DE MERLÍN EN LOS LIBROS DE CABALLERÍAS CASTELLANOS: EL APRENDIZAJE MÁGICO Y EL SABIO ENGAÑADO POR UNA MUJER
}

\author{
Daniel Gutiérrez TráPAGA \\ Universidad Nacional Autónoma de México
}

Seule Viviane l'aima, pour son bonheur, pour son malheur peutêtre, pour leur malheur ou leur bonheur à tous les deux, nous ne pouvons pas savoir, nous ne sommes pas des enchanteurs.

René Barjavel, L'Enchanteur

En la Historia Regum Britanniae (h. 1136) de Geoffrey de Monmouth, Merlín, hijo de una princesa de Demencia y de un íncubo, desaparece por completo del relato, tras ayudar a la concepción del rey Arturo. Desde este momento fundacional del personaje, las historias del universo artúrico tuvieron problemas para encontrar un final adecuado para un ser con características tan extraordinarias. El mismo autor completó la biografía de Merlín en su Vita Merlini (h. 1149-1151). Allí, el personaje se retira al bosque, donde hace sus últimas profecías y hereda sus poderes adivinatorios a su hermana. En la trilogía (h. 1191-1212) atribuida a Robert de Boron, el personaje es hijo de un plan infernal para concebir al Anticristo. Con ello, el mago se transforma en el hijo del diablo; pero, gracias al arrepentimiento de su madre, Dios lo premia con el don de la profecía. Luego, Merlín se convierte en profeta y hacedor de la voluntad divina. Tras consolidar el reino de Arturo, el personaje se aleja de éste, para recluirse en un misterioso lugar que él mismo construye, llamado el esplumoir.

Las continuaciones del Merlin de Robert de Boron del siglo XIII optaron por otra solución para explicar su alejamiento. La perteneciente al ciclo en prosa Lancelot-Graal, la Suite Vulgate, ofreció un desenlace que se volvió tan importante para la caracterización de Merlín como su ascendencia diabólica o sus capacidades sobrenaturales. El autor de esta obra recurrió a un motivo frecuente de las historias medievales: el del sabio engañado por 
una mujer, de la cual se enamora. Diversas historias de creación medieval contaron la manera en que varios personajes de la tradición bíblica y clásica, considerados magos, fueron ridiculizados o sometidos por una mujer de la cual se enamoraron, como Aristóteles, Hipócrates y Virgilio, quienes eran considerados magos. ${ }^{1} \mathrm{Al}$ respecto, Zumthor señala:

Dans tous ces récits se trouve le même thème:

a) Les femmes trament amour du Sage comme un vaste complot. Elles représentent la force insinuant du vice, en face de la puissance de l'esprit.

b) La seule faiblesse du Sage réside dans son cœur: il cède à l'amour; il s'y donne sans défense avec une sincérité d'enfant. La femme au contraire n'éprouve que de l'horreur pour celui qui l'aime. Elle garde la tête froide, joue de ses charmes, et parvient, grâce à la ruse, à s'asservir ainsi l'amoureux, l'avilir, le tuer.

c) La grandeur du Sage, voire sa noblesse moral, en sort exaltée: soit par l'éclat d'une vengeance terrible, soit par un jugement de l'auteur. ${ }^{2}$

Es claro que detrás del motivo del sabio engañado por una mujer y los aspectos que de éste señala Zumthor se encuentra la visión eclesiástica predominante sobre la mujer en la Edad Media, que parte de la responsabilidad de Eva en la expulsión del Paraíso. Robert Fossier resume así los postulados centrales de dicha concepción: «la mujer era la 'puerta del Diablo', el 'enemigo' responsable de la Caída, el símbolo de la impureza que prueba que la sangre manchada que brota inevitablemente de ella, la loba cruel devoradora de hombres, la marrana insaciable y lujuriosa. Por eso, había que odiarla aún más cuando intentaba ser amada [...]». ${ }^{3}$ Así, el hombre tenía que estar siempre atento a controlar a la mujer y evitar que ella lo sometiera.

Como veremos adelante, la historia del encierro de Merlín se inserta dentro de la tradición de los sabios y magos engañados por una mujer y participa de la tradición misógina medieval. Debido a las continuas reelaboraciones de la historia de Merlín, los motivos del engaño y el aprendizaje mágico tuvieron distintas implicaciones en cada nuevo contexto narrativo. Por ello, este trabajo tiene por objetivo revisar dichos motivos en función de la caracterización y

\footnotetext{
${ }^{1}$ La importancia de las historias de estos personajes es tal que Thompson las clasificó como motivos, incluyendo a sus personajes. Por ello, en su obra encontramos «Virgil as a magician»; «Virgil in the basket»y «Aristotle and Phyllis». Vide Stith Thompson, Motif Index f Folk-Literature. A Classification of Narrative Elements in Folktales, Ballads, Myths, Fables, Mediaeval Romances, Exempla, Fabliaux, Jest-Books, and Local Legends, Bloomington e Indianápolis, Indiana University Press, 1955, «D1711.2», «K1211»y «K1215», respectivamente, vols. II y IV:

${ }^{2}$ Paul Zumthor, Merlin le Prophéte. Un thème de la littérature polémique de l'historiographie et des romans, Ginebra, Slatkine, 2000, p. 237.

${ }^{3}$ Robert Fossier, Gente de la Edad Media, México, Taurus, 2008, pp. 89-90.
} 
valoración moral de Merlín, en los libros de caballerías castellanos, partiendo de los antecedentes franceses del siglo XIII.

En la Suite Vulgate, texto que introdujo ambos motivos a la historia del mago, Merlín trata de evitar enamorarse de Viviana, como se cuenta cuando el mago ve a la mujer por primera vez: "Al verla, Merlín la contempló durante un rato antes de decir nada y luego dijo que sería muy loco si quedara adormilado en su pecado y perdiera el sentido y el conocimiento a cambio de divertirse con una doncella, afrentándola y pecando contra Dios».. ${ }^{4}$ El pasaje muestra la conciencia que el profeta artúrico tiene del peligro que corre si se abandona al amor de una mujer. Además, poco antes de conocer a la doncella, él mismo personaje profetiza a Blaise su encierro. ${ }^{5} \mathrm{~A}$ pesar de su cautela inicial, Merlín sabe que su destino es inevitable. La obra así lo recalca, cuando relata el origen de Viviana, a través de la profecía que la diosa Diana hace al padre de la doncella: «la primera hija hembra que tengas será codiciada por el hombre más sabio de la tierra después de mi muerte [...] le enseñará la mayor parte de lo que sabe de nigromancia de tal forma que quedará sujeto a ella desde el momento en que la vea y no podrá hacer nada en contra de su voluntad»». ${ }^{6}$

Como lo predijo Diana, el profeta artúrico se enamora de Viviana, quien promete amarlo cuando él termine de enseñarle magia. Más adelante, el texto también afirma que Morgana aprendió astronomía y necromancia del mago, sin mencionar ningún otro tipo de relación entre ellos. ${ }^{7}$ Así, la enseñanza mágica permite explicar el origen de los poderes nigrománticos, tanto usados de manera positiva (Viviana) como negativa (Morgana), en el resto del texto, así como en el Lancelot en prosa. El aprendizaje de Viviana siempre permanece ligado al amor que Merlín siente por ella. Aunque el mago nunca olvida las verdaderas intenciones de la doncella, él permanece sumiso al amor de su dama, como lo haría un buen amante cortés y como él mismo reconoce ante Viviana: «[...] sé lo que pensáis y sé que intentáis retenerme, pero estoy tan sorprendido y sujeto por vuestro amor, que a la fuerza tengo que hacer vuestra voluntad». Con ello, la alumna somete al maestro, ${ }^{8}$ usando sus propios encantamientos.

Viviana encierra a Merlín mientras duerme en la torre más hermosa del mundo en el bosque de Brocelianda. El mago queda apartado definitivamente del universo artúrico y de su papel de profeta divino. Como lo ha señalado

\footnotetext{
${ }^{4}$ Historia de Merlín, trad. e introd. de Carlos Alvar, Madrid, Siruela, 2002, p. 248.

${ }^{5}$ Ibidem, p. 244.

${ }^{6}$ Ibidem, p. 247.

${ }^{7}$ Ibidem, p. 289.

${ }^{8}$ Thompson clasificó el motivo como «Pupil surpasses magician», op. cit., «L142.2», vol. 5.
} 
Zumthor, la debilidad de Merlín es la misma que la de los otros sabios: el amor. Sin embargo, el final del personaje no lo deja en ridículo, ni lo lleva a la perdición:

- Señora, me habéis engañado si no permanecéis conmigo, pues nadie, sino vos, tenéis poder para deshacer esta torre.

- Mi dulce amigo, vendré a menudo y podréis tenerme entre vuestros brazos y yo a vos; a partir de ahora podéis hacer todo lo que queráis.

Mantuvo muy bien la promesa, pues fueron pocos los días y las noches que no estuvo con él y Merlín no volvió a salir de aquella fortaleza en la que su amiga lo había encerrado, aunque ella salía y entraba siempre que quería. ${ }^{9}$

No hay en la obra una condena explícita de la situación de Merlín. Como señala Anne Berthelot: «The conclusion of this episode is near a happy ending as one could imagine $[\ldots] \gg . .^{10}$ Finalmente, Viviana cumple su promesa de amarlo, tras terminar su aprendizaje. A pesar de ello, Merlín paga el alto precio de su encierro y la pérdida de su voluntad, sometida por completo a los deseos de su doncella.

Por su parte, la Suite du Merlin, texto perteneciente al ciclo artúrico de la Post-Vulgate (h. 1230-1240), conservó los motivos del sabio engañado por una doncella y el del aprendizaje mágico. Las modificaciones a la intriga y a la caracterización de los personajes introducidas en esta obra fueron tan grandes que los motivos ya señalados adquirieron nuevos significados y funciones en este relato.

El primer gran cambio ocurre en la relación de Morgana y Merlín. Nuevamente, ella aprende magia del mago, pero la Suite $d u$ Merlin sí aclara el interés de Merlín por la hermana de Arturo: «Quand il [Merlín] vit qu'elle était d'une si grande beauté, il devint éperdument amoureux d'elle». ${ }^{11} \mathrm{El}$ profeta artúrico intenta utilizar su conocimiento para conseguir el amor de una mujer. Una vez que concluye su aprendizaje, Morgana aleja al mago de su compañía, estableciendo, como uno de los atributos negativos su lujuria: «elle chasssa Merlin de son entourage, prace qu'elle s'était bien aperçu qu'il l'amait d'un amour qui n'avait rien de chaste». ${ }^{12} \mathrm{El}$ aprendizaje de la nigromancia lleva a Morgana a ser poseída por el demonio y, por tanto, a perder su

${ }^{9}$ Historia de Merlín, op. cit., p. 440.

${ }^{10}$ Anne Berthelot, «Merlin and the Ladies of the Lake», en Peter H. Goodrich y Raymond H. Thompson, eds., Merlin. A Casebook, Nueva York y Londres, Routledge, 2003, p. 176.

${ }^{11}$ La Suite du Roman de Merlin, trad. de Stéphane Marcotte con base en la edición de Gilles Roussineau, § 157, p. 274.

${ }^{12}$ Ibídem, § 157, p. 255. 
belleza. ${ }^{13}$ Por ello, recae en Merlín la culpa de haber confiado sus poderosos hechizos a una mujer, que, por su naturaleza, sucumbe al diablo y se convierte en la principal antagonista del rey Arturo. Así, la caracterización de Merlín deja de ser la del intachable profeta que trascendió su naturaleza diabólica. A pesar de sus poderes y sabiduría, el mago guía nuevamente sus acciones con base en sus pasiones, cuando Morgana cambia la vaina mágica de la espada, que protege a Arturo de desangrarse o recibir heridas mortales. Cuando el rey descubre la traición, Merlín accede a las súplicas de Morgana y miente a Arturo al convencerlo de que alguien más le robó la vaina a su hermana. ${ }^{14}$

La relación que establecen Merlín y Nivienne vuelve más cuestionable la estatura moral del mago. El profeta se enamora de la Doncella del Lago, quien teme ser deshonrada por él. El personaje femenino pide aprender encantamientos, como condición para amar al mago, esperando poderse defender de él: «Je ne vous aimerai jamais si vous ne me promettez pas de m'apprendre tout ce que je veux savoir des enchantements que vous connaissez [...] ».15 El encantador, pensando sólo en sus deseos, no se da cuenta de que su instrucción no lo llevará a obtener su ansiado premio, pero sí a formar a otra poderosa maga : «La demoiselle se lia donc à Merlin; elle n'alla pas jusqu'à lui accorde la moindre faveur, mais il attendit le moment où il pourrait la connaître charnellement de son plein gré, espérant obtenir son pucelage, car il savait qu'elle était encore vierge. Il se mit à l'initier à la magie et aux enchantements, si bien qu'elle devint fort savant». ${ }^{16}$ La lujuria se convierte en uno de los atributos más importantes del mago en la parte final de su vida. Además, su origen demoníaco justifica que Nivienne lo desprecie: «il est fils d'une creature démoniaque et diabolique et pour rien au monde je pourrais aimer un fils de diable». ${ }^{17}$

Merlín nunca se da cuenta de las intenciones de Nivienne. Finalmente, por amor a ella, el profeta abandona a Arturo, hasta que la pareja llega a un profundo valle rocoso, donde el mago muestra a la Dama del Lago una maravillosa residencia subterránea donde yacen enterrados dos amantes. Allí, el profeta sucumbe: «Merlin éprouva un fort sentiment d'accablement qui lui ôta une bonne partie de son enjouement et de son entrain habituels. A peine couché, il s'endormit, en homme qui était déjà ensorcelé; dès ce moment, il avait perdu toute la perspicacité et toute l'intelligence dont il avait été auparavant pourvu». ${ }^{18}$

\footnotetext{
${ }^{13}$ Ibidem, § 27, p. 132.

${ }^{14}$ Ibídem, $\S 162$, p. 281.

${ }^{15}$ Ibidem, § 316, p. 494.

${ }^{16}$ Ibidem, $\S 317$, p. 494.

${ }^{17}$ Ibídem, $\S 385$, p. 566.

${ }^{18}$ Ibidem, $\S 385$, p. 565.
} 
Aprovechando el pesado sueño del profeta, Nivienne lo encierra vivo en la tumba, sellando el lugar con los encantamientos aprendidos del propio Merlín. Entonces, el mago es engañado por completo; sus conocimientos y poderes le resultan inútiles para evitar que una mujer lo venza. A pesar de que el mago nunca intenta nada contra Nivienne, su amor representa una grave falta, pues él: «abandona el camino que el Señor le había trazado al ceder a la tentación de la carne, cometiendo así una falta imperdonable y convirtiéndolo en la encarnación misma de los vicios reprobados en la novela». ${ }^{19}$

\section{Baladro del sabio Merlín}

El primer libro de caballerías castellano que retoma la historia de Merlín es el Baladro del sabio Merlín. Existen dos versiones conservadas, la publicada en Burgos en 1498 y la edición sevillana de 1535. A pesar de las diferencias entre las ediciones, ambas son una compleja adaptación de la Suite du Merlin. Respecto a la fuente francesa original, las principales novedades del Baladro y de la caracterización de Merlín están en el episodio final, el de su muerte y que da título al texto.

Como en la Suite, Merlín enseña magia a Morgana esperando ser amado. El baladro conserva los pasajes que narran cómo la nigromancia hizo que Morgana perdiera su belleza y el episodio donde el mago, a pesar de haber sido rechazado por la mujer, la protege de la venganza de Arturo, por robar la vaina mágica. ${ }^{20}$ Su relación con Niviana también sigue lo establecido en la Suite du Merlin. La Doncella Cazadora teme ser escarnecida por Merlín. Ella le pide que la instruya en magia, como condición previa al amor, y le hace prometer al profeta que no utilizará encantamientos para escarnecerla. Como en la fuente francesa, Merlín accede a tener una segunda discípula: «E començole a enseñar tanto de nigromancia e de encantamentos, que supo tanto e en algo más que el mesmo Merlín». ${ }^{21} \mathrm{~A}$ diferencia de la fuente, el impreso burgalés es explícito desde el inicio, el aprendizaje de Niviana la llevará a tener un poder superior al de su maestro.

\footnotetext{
${ }^{19}$ Rosalba Lendo, «Viviana, amante de Merlín o la Dama del Lago», en Concepción Company, Aurelio González y Lilian von der Walde, eds., Textos medievales: recursos, pensamiento e influencia, México, Universidad Nacional Autónoma de México, El Colegio de México y Universidad Autónoma Metropolitana, 2005, pp. 87-88.

${ }^{20}$ Vide El baladro del sabio Merlín con sus profecías, ed. facsimilar, transcripción e índice de María Isabel Hernández, estudios preliminares de Ramón Rodríguez Álvarez, Pedro M. Cátedra y Jesús D. Rodríguez Velasco, Oviedo, Trea, Hermandad de Empleados de Cajastur y Universidad de Oviedo, 1999, cap. XXVI, pp. 109-111.

${ }^{21}$ Ibidem, cap. XXXIV, p. 151.
} 
Luego, la pareja de nigromantes se dirige al lago de Diana y, finalmente, al valle en dirección al reino de Gorre, donde Niviana encierra a Merlín. Antes de comenzar el episodio final, hay una intervención del narrador que guía la interpretación de la caracterización de los personajes y anticipa el final: «Verdad es que Merlín fue fijo del diablo e bien se otorgó en todas las istorias; e asimesmo quél fue el más sabio ombre del mundo e que más supo de las cosas que eran por venir, sino Dios [...] E otrosí de su muerte dixo que mujer lo mataría; e él guaresció de su muerte a muchos buenos ombres e a sí mesmo no pudo guarescer [...]». ${ }^{22} \mathrm{El}$ fracaso de Merlín tiene una clara razón: el pecado: «Ca el amó por su peccado a la Donzella del Lago». ${ }^{23}$ Así, el amor le impide controlar sus impulsos y lo lleva a perder el control de la razón. Por ello, otorga de nuevo su conocimiento a una mujer, a pesar de su experiencia previa con Morgana, e ignora la ya mencionada sabiduría medieval sobre la mujer. Merlín, al enseñar magia, hace posible que sean los personajes femeninos los que asuman el control de la relación.

En el caso particular de Niviana, los motivos de la enseñanza mágica y del sabio engañado por una mujer adquieren una segunda interpretación por las modificaciones de la caracterización del personaje en el Baladro. La intervención del narrador continúa así: «era una de las más fermosas mugeres del mundo; e otrosí era muy rica e avía grant tierra; e era natural de la Pequeña Bretaña, de bautismo avía nombre Niviana. E ésta crió muchos onbres buenos e muchas dueñas e fizo mucho bien. E quando ella vio que la Merlín». ${ }^{24} \mathrm{La}$ caracterización ideal del personaje femenino, explícitamente buena, contrasta claramente con la de mago, hijo del diablo y pecador. Además, destacan los rasgos de figura materna que el texto señala. El atributo no es novedoso, pues en el Lancelot en prose, es la Dama del Lago quien se vuelve la madre adoptiva de Lanzarote, el mejor caballero terrenal. En la Suite du Merlin y en el Baladro hay un breve episodio que prepara dicho suceso. Antes de que la pareja llegue al Lago de Diana, pasan por el reino de Ban de Benuit. Allí conocen a Lanzarote de un año de edad, donde ella se muestra cariñosa y maternal con el futuro caballero. ${ }^{25}$

Finalmente, justo antes de que la doncella encierre a Merlín, ella misma establece el contraste entre ambos, en consonancia con lo afirmado previamente por el narrador:

\footnotetext{
${ }^{22}$ Ibidem, cap. XXXVIII, p. 170.

${ }^{23}$ Loc. cit.

${ }^{24}$ Loc. cit.

${ }^{25}$ Ibidem, cap. XXXV, p. 152.
} 
este ombre sabed que es fijo del diablo e sus obras fazía; e andava empós de mí por me fazer escarnio e deshonra, si pudiese; ca él creía de mí aver la virginidad, la que yo he ofrecido a Dios e nunca otro la avrá, sino Él, como Señor que todas las cosas e a mí fizo. E bien escape del fijo del diablo sin me desonrar, si pudiera; mas Dios me libró dél, que sabía mi intención e la suya. E pues que él me quería escarnecer, mejor es que escarnesca yo dél. Cierto, por mal suyo me cuidó desonrar, ca yo le acortaré su vida por lo que él contra mí pensaba fazer. ${ }^{26}$

Con ello, la diferencia entre la caracterización del encantador y la de Niviana se vuelve más extrema. Merlín actúa guiado por el diablo, mientras que la Doncella de Lago es protegida por Dios, quien permitió el engaño para evitarle daño. Por tanto, el mago ha cambiado completamente pues ha sido dominado por su naturaleza diabólica. Así, el engaño que lleva a la muerte del profeta está justificado y es necesario para detener a un emisario de Satán y proteger a una mujer que ha prometido su virginidad a Dios y que actúa según la voluntad divina.

Por ello, como en la Suite, Niviana encierra a Merlín en una cámara tras sendas puertas de hierro, con los poderosos encantamientos aprendidos de Merlín y una campana, ejecutando así la voluntad divina. Con ello, la caracterización de la doncella se asemeja mucho al gran ideal femenino del Occidente medieval: la virgen María. Como la madre de Cristo, Niviana es una virgen que funge como figura materna, tanto por el episodio con Lanzarote en el capítulo XXXV, como por la tradición del personaje, en la cual ella ya estaba plenamente identificada como la madre adoptiva del caballero. Además, como la mujer del capítulo 12 del Apocalipsis que se enfrenta a Satán, identificada con la Virgen, la Doncella del Lago sostiene su lucha contra Merlín, hacedor de las obras del demonio, y, finalmente, triunfa. Entonces, la implicación medieval tradicional del motivo del sabio engañado por una mujer, se ha invertido aquí. Es el personaje masculino quien representa la tentación y la fuerza del pecado, pues no es cualquier hombre, sino el hijo del diablo; el personaje femenino está del lado divino. El contraste entre los personajes llega al extremo, cuando el mago entrega su alma al infierno y reconoce sus obras diabólicas, pidiendo a su padre que lo lleve con él:

Pues que tú vees que ansí me escarnece mi peccado, porque Dios de mí no quiere aver aparte, ¿por qué no vienes tú por mí con tu grande e mala compaña de tus servientes e fazme aver mala fin, ca yo soy tu carne? Ven e tómame, que de ti vine por mala ventura e a ti me quiero tornar; que yo soy tuyo de

${ }^{26}$ Ibidem, cap. XXXVIII, p. 174. 
comienço; que siempre fize tus obras. E yo no quiero ni amo sino a ti e a ti ruego e a ti demando que me no me dexes. ${ }^{27}$

La transformación de Merlín en un ser diabólico es definitiva, igual que su condena. Entonces, la historia del profeta tiene un gran valor didáctico, donde el comportamiento ejemplar se encuentra representado por Niviana, mientras que la historia del mago sirve de advertencia sobre los peligros del pecado (aunque sólo sean de pensamiento), someterse a las mujeres y al diablo.

\section{Espejo de caballerías (libro II) de Pedro López de Santa Catalina}

Los libros I y II del Espejo de caballerías, de Pedro López de Santa Catalina, fueron publicados en Toledo en 1525 y en 1527, respectivamente. Ambas obras son una compleja adaptación prosística del Orlando Innamorato de Matteo Boiardo y de sus continuaciones, con material del Amadís de Gaula, las Sergas y episodios originales. ${ }^{28}$

Estas obras, como el poema de Boiardo, tratan de las aventuras de dos caballeros de la corte de Carlomagno, Rolando y Renaldos de Montalván, siempre vinculadas con Angélica la Bella. La primera vez que aparece una discípula de Merlín es cuando Angélica es llevada por un monstruo al interior de una laguna. Al encontrarse en un lugar maravilloso, Angélica pregunta a una dueña dónde se encuentra: «Sabed que estáis en los aposentos del Lago Ferviente, que agora llamáis los de Francia la Blanca Laguna y es uno de los maravillosos y mayores encantamientos que yo en mi tiempo hice con mi saber e del sabio Merlín, que fue hijo del diablo. Sepas que yo soy la fada Morgana y el rey que viste es el rey Artur de Bretaña». ${ }^{29}$ Como veremos, luego se aclara qué ocurrió entre ambos hechiceros.

Tras haber bebido del agua de la fuente del desamor (hecha por Merlín), gracias a Malgesí, Roldán lamenta haberse enamorado de Angélica. ${ }^{30}$ La noche sorprende al caballero en unos valles infernales, por lo que entra a una capilla, donde hay un sepulcro sobre el cual hay una figura de piedra del diablo. Tras escuchar horribles e infernales baladros, Roldán observa algo más temible que el ominoso valle:

${ }^{27}$ Ibídem, cap. XXXVIII, pp. 177-178.

${ }^{28}$ Vide Javier Gómez-Montero, Literatura caballeresca en España e Italia (1483-1542). El «Espejo de caballerías» (Deconstrucción textual y creación literaria), pp. 28-60.

${ }^{29}$ Pedro López de Santa Catalina, Libro segundo de Espejo de caballerías, ed. de Juan Carlos Pantoja Rivero, Alcalá de Henares, Centro de Estudios Cervantinos, 2009, cap. VI, p. 18.

${ }^{30}$ Además, la dama está muerta desde el capítulo XXI, donde Malgesí ordena a sus demonios familiares ahogarla para evitar más desaguisados causados por su amor, ibídem, cap. XXI, p. 71. 
[...] todo lo que viese era fuera de naturaleza humana y gran compañía diabólica, la cual, andando al derredor del sepulcro traía en medio de sí un hombre vestido de unas ropas de fuego que todo le cubrían, el cual fazía el mayor llanto del mundo, maldiziendo a sí mesmo y a quien engendrado le avía, y a la madre que la avía criado, y todo el tiempo que avía vivido, y a la muerte que no le matava, y al su tormento infernal porque no le consumía. E respondíale aquellos fieros y espantables vestiglos que le traían: - ¡Calla, Merlín, no maldigas a quien culpa de tu perdición no tiene!. A ti maldí cada hora, que te perdiste y a ti mesmo te truxiste a estas penas: tú tienes la culpa de tu tormento ${ }^{31}$

La escena, que hace temblar de miedo al más valeroso paladín de Francia, presenta la tortura infernal a la que está sometido Merlín, a pesar de sus otrora poderosos hechizos. El personaje sufre grandemente, pero los diablos le recuerdan que todo lo que le sucede se debe a sus acciones, motivadas por el amor y por la magia que él mismo enseñó:

Cata aquí el sepulcro donde te encerró aquella que con tu saber heziste maestra muy más sabia que tú, la cual, aunque al presente se dilata á de venir también como tú a nuestro poder. Aún tú te avías de alegrar porque cada noche te traemos a visitar este lugar en el cual desseavas tú con tu enamorada Morgaina deleitarte y tomar placer. Y pues tus locos amores de tu muerte fueron causa, cúlpate a ti, que así por amor de un flaca mujer, te dexaste vencer. Cata que los enamorados, por servicio de sus amigas, mucho an de sofrir e padecer: no te pese que tal pena padezcas, pues la padeces por quien tanto quisiste; por quien tanto amaste de coraçón ten paciencia, que tanto serás entre los enamorados estimado e tenido cuanto más padecieres y sufrieres. ${ }^{32}$

De manera sintética y analéptica, las acciones de Niviana al final del $B a$ ladro, son asimiladas al personaje de Morgana. Sin embargo, la hermana de Arturo no alcanza una caracterización positiva, pues los diablos también la aguardan tras su muerte.

Aquí, vuelve a aparecer el vínculo entre el motivo de la enseñanza mágica y el del sabio engañado por una mujer con sus propias artes. Los diablos ridiculizan al mago por haber sido derrotado por una simple mujer. Con su sufrimiento por Morgana, Merlín gana fama como fiel enamorado, pero a costa de la condena de su alma. Así, su sabiduría y poderes no le sirvieron para nada, pues, al someterse a una mujer, ni consiguió el amor en vida, ni ganó la salvación. Por su parte, Morgana también será condenada, a pesar de superar

\footnotetext{
${ }^{31}$ Pedro López de Santa Catalina, op. cit., cap. XXX, p. 97.

${ }^{32}$ Ibidem, cap. XXX, p. 98.
} 
a su maestro. Ninguno de los dos puede encausar sus poderes y sabiduría para lograr la salvación. Por ello, ambos originan su perdición.

La tragedia de Merlín y su impresionante tortura sirven a un propósito moralizante sobre el amor cortés y las mujeres, ${ }^{33}$ tanto para el lector, como para Roldán. Así, lo hace explícito el narrador al suspender brevemente la historia y solicitar al lector que reflexione sobre la semejanza entre la historia del mago y la del paladín carolingio:

Agora piença, discreto lector, qué sentiría el buen conde don Roldán viendo hazer delante de sí tal justicia a un tal hombre que por tan sabio avía sido en este mundo tenido. Y viendo a sí mesmo culpado de la mesma culpa de amor, por el cual tantos peligros avía pasado y avía sido causa de tantos males, compungíase en su coraçón tan agramente, que las lágrimas y sospiros daban testimonio de su arrepentimiento. ${ }^{34}$

Si el comportamiento amoroso de Merlín es presentado como un exemplum ad contrarium, el de Roldán resulta ejemplar en la medida en que se arrepiente de su amor por Angélica y reconoce los defectos del amor cortés. Al respecto, Javier Gómez-Montero señala: «[...] el episodio posee una notoria significación moral, pues en él se confirma el cambio definitivo de la actitud del héroe. El arrepentimiento de Roldán significa la expiación de las pasadas culpas, de sus 'locos amores' que, además, Roldán ya reconoce como tales». ${ }^{35}$ Para recalcar la advertencia contra el amor, además de mostrar a Merlín engañado, derrotado y condenado al infierno, hay una amplia y sádica descripción de su tortura, acorde al pecado que cometió. La boca, por los besos, es castigada con fuego; los ojos, con los que miraba a Morgana, le son sacados y su cuerpo es descuartizado. ${ }^{36}$ Luego, los pedazos de Merlín se reconstituyen para que los diablos regresen el alma del mago al infierno, para repetir la tortura al día siguiente.

\section{Tristán de Leonís y el rey don Tristán su hijo}

En 1534 aparece en Sevilla el Tristán de Leonís y el rey don Tristán el Joven, su hijo. Dicha obra contiene el Tristán de Leonís de 1501, como «Libro

\footnotetext{
${ }^{33}$ Merlín no cumple con el requisito fundamental de ser caballero para ser considerado amante cortés; sin embargo, la descripción que Pedro de la Sierra hace de su amor concuerda con la manera en que se estructuran dichas relaciones: «Cata que los enamorados, por servicio de sus amigas, mucho an de sofrir e padecer». Ello muestra el sometimiento incondicional del mago a los deseos de su dama.

${ }^{34}$ Pedro López de Santa Catalina, op. cit., cap. XXX, p. 98.

${ }^{35}$ Javier Gómez-Montero, op. cit., p. 169

${ }^{36}$ Pedro López de Santa Catalina, op. cit., cap. XXX, p. 98.
} 
primero», y una continuación original, Tristán el Joven, como «Libro segundo», donde se narran los hechos de los hijos, Tristán el Joven y la infanta Iseo. Para hacer posible la aparición de los dos nuevos personajes se agregó una interpolación a la historia de Tristán de Leonís, donde la desastrada pareja concibe a su descendencia. La interpolación corresponde a los capítulos XXVII-LXI. Ésta ocurre cuando Tristán viaja de Irlanda a Cornualles, para llevar a Iseo como esposa al rey Mares. Tras beber accidentalmente el filtro y consumar su amor, la pareja llega a la Ínsula del Ploto. El caballero la conquista y la pareja permanece dos años en la isla. Allí, Iseo da a luz a los protagonistas de la segunda parte.

En este tiempo, Tristán recibe la noticia de que existe en la isla una región abundante en caballos, llamada Florisdelfa, que pertenece una doncella homónima:

Y esta donzella, por razón que nació en aquella villa, la nombró su padre Florisdelfa. Y es señora de aquella tierra. Y sus padres ha mucho que murieron y no se ha querido casar. Y es muy gran sabidora de las artes mágicas. Y es así que, en vida de su padre, aportó a Florisdelfa Merlín, a causa de una tormenta que allí le echó. Y en gran manera fue servido d'esta donzella. Y Merlín, por la gratificar, enseñóle cumplidamente las artes mágicas. ${ }^{37}$

Aquí aparece el tópico del aprendizaje mágico. Nuevamente, Merlín enseña sus artes a una doncella. En esta ocasión, la transmisión de poderes no trae consecuencias adversas al mago artúrico, ni termina engañado por una doncella. La presencia de Merlín, a través de una analepsis, permite caracterizar a Florisdelfa, explicando el origen de sus poderes y su conversión en maga. Aunque el pasaje menciona que la doncella sirvió grandemente al mago, el texto no afirma explícitamente una relación amorosa. Sin embargo, los antecedentes de la tradición de Merlín, quien sólo enseña magia a las mujeres que intenta seducir, sugieren la existencia del amor del profeta artúrico por Florisdelfa. Sobre la relación entre esta mujer y el mago, Axayácatl Campos afirma: «De cierta forma, su vínculo con el personaje artúrico constituye una manera de conferir a su saber un toque de autoridad y tradición. Sin embargo, Florisdelfa, como Merlín, sucumbe al poder del amor y queda imposibilitada para interpretar correctamente los indicadores de la magia»». ${ }^{38}$ En efecto, exista

${ }^{37}$ Tristan de Leonís y el rey don Tristán el Joven, su hijo, ed. de María Luzdivina Cuesta Torre, México, Universidad Nacional Autónoma de México, 19997, cap. XLVII, pp. 250-251.

${ }^{38}$ Axayácatl Campos García Rojas, «'Nunca le plugo ni consigo pudo de averse de casar': mujeres solteras, intelectuales y brujas en los libros de caballerías hispánicos», en Marina Fe, coord., Mujeres en la hoguera. Representaciones culturales y literarias de la figura de la bruja, México, Universidad 
o no la relación amorosa entre Merlín y Florisdelfa, es claro que la fallida relación de ésta con Tristán tiene similitudes con los fracasos del encantador. Así, la tradición del profeta anticipa la tragedia amorosa de la maga.

Más adelante, ella se enamora de Tristán, sin sospechar la existencia de Iseo, pues: «por su arte mágica, supo que le venía una embaxada del mejor cavallero del mundo, y preguntó a un espíritu mucho su familiar, si era gentilhombre y si era casado. Fuele respondido que era gentilhombre y que no era casado».$^{39} \mathrm{Al}$ llegar con Tristán y ver la belleza de la princesa irlandesa, la maga: «como iva sin sospecha que Tristán no tenía muger, trastornósele el coraçón y súpitamente perdió el seso y con boz terrible dixo: ‘ $¡ O$, espíritu enemigo mío, cómo me as burlado!' Y dicho esto, volvió con gran ímpetu las espaldas y fuesse corriendo al mirador y despeñóse de allí abaxo». ${ }^{40}$ Así, el uso de la magia aprendida de Merlín, opera en contra de la propia Florisdelfa. Sus espantosos gritos y reclamos antes de morir, también recuerdan a los del Merlín antes de entregar su alma al diablo, en el Baladro. Ella culpa al espíritu que consultó; sin embargo, éste nunca mintió, pues Tristán no es un hombre casado, lo que es una respuesta verdadera a la pregunta de la maga Por tanto, el uso de la magia para obtener el amor termina funcionando en contra de la doncella, al no poder controlar y entender la información obtenida a través de la nigromancia.

\section{Baldo (1542)}

El Baldo es el cuarto libro del ciclo de Reinaldos de Montalbán. El libro fue impreso por única vez en Sevilla en 1542 y es una complejísima adaptación de distintas fuentes, con episodios originales. ${ }^{41}$

En la isla de Muselina, Bimazo, centauro adversario de la maga que da nombre al lugar, lleva a Baldo y otros personajes al sepulcro de Merlín, para enterrar al padre del protagonista, a Guidón, y al caballero Leonardo: «Aquí estuvo sepultado el sabio Merlín, engañado por una muger, el cual sacó don Tristán de Leonís, y en señal d'esto, está metido dentro un demonio llamado Rubicán» ${ }^{42}$ El texto no dice más del profeta artúrico, aunque sintetiza el

Nacional Autónoma de México-Programa Universitario de Estudios de Género, 2009, pp. 101-102.

${ }^{39}$ Tristan de Leonís y el rey don Tristán el Joven, su hijo, op. cit., cap. XLVIII, p. 252

${ }^{40} \mathrm{Ibídem}$, cap. XLIX, pp. 255-256.

${ }^{41} \mathrm{El}$ «Libro I», hasta el capítulo XXXV, adapta el poema macarrónico latino Baldus (1521) del italiano Teófilo Folengo; el «Libro II» adapta la Eneida de Virgilio; y el «Libro III» añade a adaptación de la Eneida episodios del Bellum civille de Lucano. Vide Folke Gernert, «Introducción», en Baldo, Alcalá de Henares, Centro de Estudios Cervantinos, 2002, pp. IX-XVII.

${ }^{42}$ Ibidem, cap. XXV, p. 93. 
motivo del sabio engañado por una mujer anónima. Además de explicar la presencia del demonio, la brevedad de la referencia hace pensar que dicho motivo en la biografía de Merlín era suficientemente conocido para resumirla de tal manera y omitir el nombre de la mujer. Así, el significado del motivo está plenamente centrado en la importancia que tiene para explicar la situación del mago, llevando a un segundo plano al personaje femenino. El castigo del mago está minimizado, pues Tristán lo logra rescatar. ${ }^{43}$ De cualquier manera, la referencia a Merlín es efímera y ayuda a justificar la presencia del demonio.

\section{Belianís de Grecia (III y IV) de Jerónimo Fernández}

En 1547, salió de las prensas burgalesas el Belianís de Grecia (Primera y Segunda partes), de Jerónimo Fernández. La Tercera y quarta parte del imbencible príncipe don Belianís de Grecia, del mismo autor, apareció de manera póstuma en 1579. En la obra de 1547, el mago Fristón hace un encantamiento de Medea con el que rapta a todas las princesas y que da fin al libro. ${ }^{44}$ Para desencantarlas, Belianís debe encontrar a Merlín. ${ }^{45}$

Tras salir del Castillo de la Fama, ${ }^{46}$ el caballero llega a un espantoso valle poblado de demonios donde escucha unos temibles y demoníacos baladros, ${ }^{47}$ hasta que llega al sepulcro de donde proviene la voz, para preguntar quién se encuentra allí:

a esta voz le paresció al príncipe que dentro se huviesse sonado el espantoso ruido con gran número de cadenas, y dende a poco le respondieron. Sábete príncipe griego que soy el más maldito hombre que en el mundo hubo, yo soy hijo del diablo y en saber sobrepujé a todos los nacidos permitiendo el Alto Señor que fuesse el mayor adivinador y máxico que en el universo huvo, donde devolbiéndole en mal bino a quien cerrado por una donzella de cuyos

${ }^{43}$ En la tradición castellana, el rescate a manos de Tristán es mencionado en el Baladro, cuando Merlín profetiza desde su encierro a Bandemagús que el único que podrá abrir su tumba será el caballero de Leonís, vide El baladro del sabio Merlín, op. cit., cap XXXVIII, p. 174. El pasaje esta retomado de la Suite du Merlín, op. cit., § 386, p. 567. Sin embargo, el episodio de Tristán no parece haberse conservado.

${ }^{44}$ Jerónimo Fernández, Belianís de Grecia, ed., introd. y notas de Lilia E.F. de Orduna. Kassel, Reichenberger, 1997. 2. ${ }^{\circ}$ v., cap. LVIII, p. 464.

${ }^{45}$ Ibídem, cap. LVIII, p. 466.

${ }^{46}$ Vide Jerónimo Fernández, Tercera y quarta parte del imbencible príncipe don Belianís de Grecia, en que se cuentan la libertad de las princessas que de Babilonia fueron llevadas con el nacimiento y hazañas del no menos valeroso príncipe Belflorán de Grecia, su hijo, Burgos, Pedro de Santillana, 1579. [Real Academia Española, R-105], III, caps. X y XIX-XX. La transcripción es mía, sólo modernizo acentuación y uso de mayúsculas.

${ }^{47}$ Ibidem, III, cap. XXI, fols. 53r-53v. 
amores yo fui preso enseñándole quanto yo sabía, y aun más pues me bastó a engañar, solían me llamar en tiempo del rey Artús el sabio Merlín. ${ }^{48}$

Entonces, el propio mago explica, lamentándose, la razón de su encierro: enseñó magia a una doncella de la cual se enamoró, quien terminó engañándolo con sus propios hechizos. Tras varias batallas, Belianís logra liberar al mago, pero no deja de señalarle sus pecados y de alentarlo para ganar el perdón: «quan mal empleado estava vuestro saber en esta temerosa sepultura, y que enmendando de aquí en adelante en lo que al Alto Señor offendistes os perdonará lo que hasta ahora contra Él herrastes. Assí lo espero yo mi señor dixo Merlín». ${ }^{49}$ El profeta artúrico afirma su deseo de arrepentimiento y deja atrás sus pecados. Inmediatamente, el mago, como lo hiciera con Arturo y su reino, pone sus capacidades mágicas y adivinatorias al servicio de la mejor caballería cristiana, dejando de usar sus poderes para tratar de conquistar doncellas.

Aquí, los motivos del sabio engañado por una doncella y el aprendizaje mágico sólo interesan en lo que concierne a la caracterización de Merlín y de Belianís. Por ello, el texto no identifica a la doncella, ni desarrolla la historia entre el mago y la mujer. En cuanto a Belianís, la gran aventura del rescate de Merlín, un descensus ad inferos, permite reiterar su caracterización de mejor caballero. Inclusive, el caballero griego supera a los mejores de la época artúrica, como a Tristán, según lo afirma el propio Merlín: «yo pensé ser libre por el valeroso don Tristán, mas mi ventura causó que nunca por aquí viniesse: [...]: no ay otro en el mundo dixo Merlín, que lo pueda hazer sino tú porque en los amores y armas has sobrepujado al que de aquí me havía de sacar: mas sábete que lo que él con poco trabajo pudiera hazer as tú de acabar con mucho».$^{50}$

La aparición de Merlín depende completamente de las necesidades de caracterización del caballero y de la aventura del desencanto de las princesas. Por tanto, el que acompañe a Belianís el más prestigioso mago de la tradición caballeresca europea, para validar aún más sus hazañas. Por ello, no hay gran desarrollo del engaño y el enamoramiento de Merlín. Basta con que, tras su liberación, el protagonista lo amoneste al respecto y que el mago afirme rápidamente su arrepentimiento. En el resto del libro, Merlín tiene varias apariciones y en ninguna de ellas recae en sus conductas pecaminosas. El mago ha escarmentado e incluso encuentra muestras de que ha sido perdonado. Por ejemplo, Merlín se encarga de proteger a Belflorán, hijo de Florisbella y

\footnotetext{
${ }^{48}$ Ibidem, III, cap. XXI, fol. 53v.

${ }^{49}$ Loc. cit.

${ }^{50}$ Loc. cit.
} 
Belianís. El niño, concebido en secreto, como el matrimonio de sus padres, nació en el castillo de Medea. Merlín se lleva al bebé para ser criado en otro lugar, ${ }^{51}$ manteniendo con ello en secreto el matrimonio de los protagonistas, evitándole problemas a la princesa babilonia, quien se convirtió al cristianismo y se desposó sin consentimiento paterno. Ella encomienda a Merlín que bautice al niño. El mago cumple con su cometido cristiano y luego encarga su crianza a la duquesa Darasola y a un ermitaño:

[...]mas aunque Merlín supiesse mucho al saber que por el alto señor hera al su deboto comunicado no igualava que a la ora conosció quién era el infante y que le traía, y bolviéndose a él le dixo. Mira Merlín el cuidado que te cumple tener de este príncipe que te será pedido, tan maravillado fue Merlín de lo que el hermitaño le dezía, y bien vio que aquello [61v.] procedía de la superna mano que a su siervo lo comunicava: entonces le quisiesse dexar en aquella hermita y venirse con él para tener cuidado de la doctrina de aquel príncipe que aquel servicio sería a Dios tan aceptó como otras disciplinas que pudiesse hazer. ${ }^{52}$

Con ello, se retoma la caracterización intachable del mago, quien aprende de su costoso error y es perdonado por Dios.

\section{Espejo de príncipes y caballeros (parte II) de Pedro de la Sierra}

La segunda parte del último gran ciclo de libros de caballerías castellanos fue escrita por Pedro de la Sierra y apareció en Alcalá de Henares en 1580. Merlín aparece directamente en la historia, en la aventura del castillo del rey de Arabia que enfrenta el caballero Claridiano, hijo de Claridiana y el Cavallero del Febo, y principal protagonista de la parte final de la obra. Al entrar a una amplia sala pintada con demonios, el caballero escucha terribles gritos y ve una tumba con un hombre sobre ella, que es torturado con fuego. ${ }^{53}$ En un principio, el hombre sobre la tumba se presenta como el rey de Arabia. ${ }^{54}$ Luego, Claridiano enfrenta a una doncella que sale de la tumba e intenta engañarlo pidiéndole un anillo que lo protegía de los encantamientos. El hombre de la tumba pide ser liberado por el caballero. Ante la duda de Claridiano, el personaje se identifica de nuevo: «-Merlín el infeliz soy -respondió- nacido en la infeliz Galia, que engañado fui de la que a ti engañar quería. Y

\footnotetext{
${ }^{51}$ Ibidem, III, cap. XXIV, fol. 61r.

${ }^{52}$ Ibidem, III, cap. XXIV, fols. 61r.-61v.

${ }^{53}$ Ibídem, II, cap. XXI, p. 241.

${ }^{54}$ Loc. cit.
} 
bien me puedes dar crédito, que te digo verdad, pues del hazer lo que te digo me viene a mí tanto provecho»». ${ }^{55} \mathrm{La}$ identidad de este personaje no es clara, como observa José Julio Martín Romero: «En este momento la narración es un tanto confusa, ya que parece identificarse al Rey de Arabia con Merlín, pero no se explica cómo lo engañó la doncella [...] Todo ello recuerda más al mago del Rey Arturo. Además, la historia del Rey de Arabia y la tumba de Merlín recuerdan al Baladro del sabio Merlín». ${ }^{56} \mathrm{El}$ resto del episodio reitera que el personaje es Merlín. ${ }^{57}$ Además, aparece el motivo del sabio engañado por una mujer. Aquí, el desarrollo del motivo es pobre. Se ignora el nombre de la doncella, no se sabe si hubo aprendizaje mágico, tampoco hay mención del amor del mago. Por ello, el contradictorio episodio muestra que el motivo del engaño y el del aprendizaje mágico estaban suficientemente asociados a la historia de Merlín, pues, de otra manera, los indicios textuales son insuficientes para interpretar la aventura del encierro del personaje artúrico.

\section{Conclusión}

Los motivos del aprendizaje mágico y el del sabio engañado por una mujer eran indisociables del encierro final de Merlín en los libros de caballerías castellanos. Es claro también que el desarrollo en la intriga de estos motivos es mucho menor que en las versiones francesas del siglo XIII, con excepción del caso del Baladro. En las descripciones del encierro del mago, presentes en el Espejo de caballerías (II), Belianis (III y IV) y el Espejo de príncipes y caballeros (II), se muestra la gran influencia del Baladro en la transmisión de la historia del mago y los motivos asociados a ella. Esto no descartó la variación de la intriga o de las implicaciones de los motivos señalados en la caracterización del personaje, ni la posibilidad de vincularlos a episodios novedosos como el del Tristán de 1534.

También se observa una gran simplificación en el desarrollo de los motivos en la intriga en las obras más tardías, llegando a los casos extremos del Baldo y del Espejo de príncipes y caballeros, donde se enuncia el engaño, como si se tratara de un índice de motivos. Esto tiene distintas implicaciones en distintos niveles del relato. Para los personajes es claro que los motivos señalados importan en la medida en que caracterizan a Merlín. Por ello, el personaje femenino que engaña al mago carece de nombre en la mitad de los

\footnotetext{
${ }^{55}$ Ibidem, II, cap. XXI, p. 242.

${ }^{56}$ José Julio Martín Romero, «Espejo de príncipes y caballeros (segunda parte)» de Pedro de la Sierra. Guía de lectura, Alcalá de Henares, Centro de Estudios Cervantinos, 2001, p. 49.

${ }^{57}$ Pedro de la Sierra, op. cit., II, cap. XXI, p. 242.
} 
textos analizados. De cualquier manera, el profeta artúrico cae por amor y por su propia magia. En el caso del Baladro y el Espejo de Caballerías (II), los personajes femeninos tienen un papel importante en la trama y para Merlín. En el primer texto, Niviana sirve de contraste al hijo del diablo y asume sus misiones divinas, en oposición a la caída infernal del mago. En ambas obras, la historia de Morgana establece paralelismos con la de Merlín, mostrando como el pecado y el mal uso de la magia llevan al infierno.

La simplificación en el desarrollo de los motivos generó que algunos de los puntos indispensables de éstos, señalados por Zumthor, no sean explícitos en la intriga. Sin embargo, la consolidada tradición del desenlace de Merlín vinculado al motivo del engaño y el aprendizaje mágico, permitía obviar su desarrollo narrativo. Por ello, varios textos no explican cómo se dio el engaño, aunque éste aparece ligado al aprendizaje mágico y es posible gracias a la debilidad del amor. Con excepción del Baladro, el resto de los textos mantiene una interpretación uniforme de los motivos, donde la mujer representa el pecado y se mantiene seductora, a la vez que es fría y calculadora. Para invertir dichas asociaciones, el Baladro desarrolló más que ningún otro texto dichos motivos, con el fin de consolidar los aspectos positivos en Niviana y los negativos en Merlín, aunque en el caso de Morgana, la caracterización negativa del personaje femenino se conservó según la tradición. De cualquier manera, el resto de las obras aquí estudiadas tomaron distintas perspectivas sobre la valoración del personaje. En los títulos pertenecientes al paradigma inicial o "idealista" de los libros de caballerías castellanos, ${ }^{58}$ como el Baladro y el Espejo de Caballerías, los motivos de la enseñanza mágica y el engaño muestran a un personaje diabólico, cuya historia tiene alto valor didáctico. En textos más tardíos del paradigma de entretenimiento, como el Espejo o el Belianis, la condena infernal de Merlín producida por los motivos ya referidos tiene menor importancia, pues dominan los elementos espectaculares que esta aventura o el mago pueden aportar al relato.

Recibido: 23/05/2011

Aceptado: 11/07/2011

\footnotetext{
${ }^{58}$ Para la evolución del género y sus paradigmas vide José Manuel Lucía Megías, «Los libros de caballerías castellanos: entre el texto y la imprenta», en Aurelio González y María Teresa Miaja de la Peña, eds., Caballeros y libros de caballerías, México, Universidad Nacional Autónoma de México-Facultad de Filosofía y Letras, 2008, pp. 183-207.
} 


\section{$\cos$}

RESUMEN: El presente trabajo estudia dos motivos recurrentes en el desenlace de la historia de Merlín en los libros de caballerías castellanos: el aprendizaje mágico y el sabio engañado por una mujer. Ambos están ligados a conocidos personajes de la tradición artúrica, como Morgana y Niviana, y al amor que el mago siente por ellas. En la tradición castellana del siglo XVI, los dos motivos señalados fueron centrales para la caracterización del mago, pero su interpretación varió en cada obra.

ABSTRACT: The present work studies two frequent motives in Merlin's story ending in Castilian Chivalric Romances: the wise-man fooled and magic learning. Both motives are linked to well known female characters in Arthurian tradition, like Morgane le Fay and Niniene, and the wizard's love for the two of them. In the Xvith century Castilian tradition, the motives already mentioned were central for Merlin's characterization. Nonetheless, its interpretation and uses changed in each text.

Palabras claves: Merlín. Libros de caballerías castellanos. Sabio engañado y enseñanza mágica.

Keywords: Merlin. Castilian Romance of Chivalry. Wise-man fooled and magic teaching. 
